\title{
HOW'S LIFE? COMBINING INDIVIDUAL AND NATIONAL VARIABLES TO EXPLAIN SUBJECTIVE WELL-BEING
}

\author{
John F. Helliwell \\ Working Paper 9065 \\ http://www.nber.org/papers/w9065 \\ NATIONAL BUREAU OF ECONOMIC RESEARCH \\ 1050 Massachusetts Avenue \\ Cambridge, MA 02138 \\ July 2002
}

The views expressed herein are those of the author and not necessarily those of the National Bureau of Economic Research.

(C) 2002 by John F. Helliwell. All rights reserved. Short sections of text, not to exceed two paragraphs, may be quoted without explicit permission provided that full credit, including (C) notice, is given to the source. 
How's Life? Combining Individual and National

Variables to Explain Subjective Well-Being

John F. Helliwell

NBER Working Paper No. 9065

July 2002

JEL No. F0, I0, Z0, J1

\begin{abstract}
This paper attempts to explain international and inter-personal differences in subjective well-being over the final fifth of the twentieth century. The empirical work makes use of data from three waves of the World Values survey covering about fifty different countries. The analysis proceeds in stages. First there is a brief review of some reasons for giving a key role to subjective measures of well-being. This is followed by a survey of earlier empirical studies, a description of the main variables used, a report of results and tests, and discussion of the links among social capital, education, income and well-being.

The main innovation of the paper, relative to earlier studies of subjective well-being, lies in its use of large international samples of data combining individual and societal level variables, thus permitting the simultaneous identification of individual-level and societal-level determinants of well-being. This is particularly useful in identifying the direct and indirect linkages between social capital and well-being.
\end{abstract}

John F. Helliwell

Department of Economics

University of British Columbia

\#997-1873 East Mall

Vancouver, BC V6R 1C2

and NBER

john.helliwell@ubc.ca 


\title{
How's Life?
}

\section{Combining Individual and National Variables to Explain Subjective Well-Being}

\author{
John F. Helliwell ${ }^{1}$
}

\section{Introduction}

This paper attempts to explain international trends and differences in subjective wellbeing over the final fifth of the twentieth century. This will be done in several stages. First there will be a brief review of some reasons for giving a central role to subjective measures of wellbeing. This will be followed by sections containing a survey of earlier empirical studies, a description of the main variables used in this study, a report of results and tests, discussion of the links among social capital, education, and well-being, re-estimation of the final model, and

${ }^{1}$ Department of Economics, University of British Columbia. The first draft of this paper was prepared when I was enjoying the hospitality of St Catherine's College, Oxford, where I was Christensen Visiting Fellow in the first half of 2001. I am grateful variously for advice, assistance, corrections, and suggestions from Robert Amano, Sudhir Anand, Michael Argyle, Aileen Battye, Andrew Clark, Kerstin Enflo, John Flemming, Bruno Frey, David Halpern, Tom Healy, Brian Henry, Jane Jenson, Thomas Lemieux, Paul Kind, Avner Offer, Andrew Oswald, Robert Putnam, Andrew Sharpe, Alois Stutzer, Tom Sander, Julia Simon, Sarah Stewart-Brown, Ian Walker, Michael Woolcock, and from participants during presentations of earlier versions at the Universities of Cambridge, Oxford, Warwick and York in the United Kingdom, the Bank of Canada in Ottawa, the Weatherhead Center for International Affairs conference at Talloires, the Policy Research Initiatives conference in Ottawa, the University of British Columbia, and the University of Osaka. E-mail comments to john.helliwell@ubc.ca. 
concluding comments.

\section{Why Study Happiness?}

The idea of using self-assessments of well-being, or of life satisfaction, as a way of evaluating the quality of a society and its citizens goes back to Aristotle and beyond. It has been argued that ancient ethics "gets its grip on the individual at this point of reflection: am I satisfied with my life as a whole, and the way it has developed and promises to develop?" (Annas 1993, 28).

The Aristotelian view has central importance among ancient and modern views, in part because of its attempt to balance different aspects of satisfaction regarded as antithetical by others. "We may define happiness as prosperity combined with excellence; or as independence of life, or as the secure enjoyment of the maximum of pleasure; or as a good condition for property and body, together with the power of guarding one's property and body and making use of them. That happiness is one or more of these things, pretty well everyone agrees. From this definition of happiness it follows that its constituent parts are: good birth, plenty of friends, good friends, wealth, good children, plenty of children, a happy old age, and also such bodily excellences as health, beauty, strength, large stature, athletic powers, together with fame, honour, good luck and excellence. (Aristotle, Rhetoric, 1360b, 14-23) ${ }^{2 \%}$. These are views Aristotle considers to be widely held. In developing his own ethical theory, Aristotle emphasizes the importance of a lifetime's virtuous activity, which in turn requires a sufficient supply of external goods if anything is to be achieved. The material goods are a means and not an end". Thus "The

${ }^{2}$ Unless otherwise specified, any quotations from Aristotle are drawn from the Barnes (1984) edition of the works of Aristotle, with page references keyed to Bekker's standard 1831 edition of the Greek text.

${ }^{3}$ For example: 'Happiness, therefore, must be some form of contemplation. But, being a man, one will also need external prosperity; for our nature is not self-sufficient for the purpose of contemplation, but our body must also be healthy, and have food and other attention. Still, we must not think that the man who is to be happy will need many things or great things, merely because he cannot be blessed without external goods; for self-sufficiency and action do not depend on excess, and we can do noble acts without ruling earth and sea; for even with moderate 
Life of money-making is one undertaken under compulsion, and wealth is evidently not the good we are seeking; for it is merely useful and for the sake of something else." (Nicomachean Ethics Book 1: 1096a 6-10). The Stoics differed from Aristotle in placing their whole emphasis on the virtuous life, while Epicureans placed more emphasis than Aristotle on the importance of pleasures, including among these the avoidance of pain in body and soul (Annas 1993, 336).

When faced with such widespread views about the constituents of happiness and the sources of life satisfaction, Aristotle also made a strong appeal for empirical work: "We must therefore survey what we have already said, bringing it to the test of the facts of life, and if it harmonizes with the facts we must accept it, but if it clashes with them we must suppose it to be mere theory." (Nicomachean Ethics, Book 10, 1179, 20-23)

This paper takes up Aristotle's challenge, as has much of the previous empirical work on subjective well-being, especially in psychology. Beyond the inherent interest of mapping the correlates of satisfaction, there are also policy-related reasons for paying attention to subjective measures of well-being. One is that many public policies have effects on well-being that flow through productivity and incomes as well as through other channels. Conventional economic analysis can recognize the existence of these other channels, but if the effects are generally positive via one channel but negative through another channel, the net effects of the policy cannot be evaluated unless there is some method for comparing the sizes of the offsetting effects. If there are ways of tracking the offsetting influences through to subjective well-being, then measures of their relative size may be used to support inferences about the net effects of events or policies under review.

Finally, the large international sample of individual well-being data permits the joint advantages one can act excellently...' (Nicomachean Ethics Book 10: 1178b 32-35, 1179a 1-5.) 
estimation of individual and societal-level linkages. This two-level approach is vital for estimating the extent to which there are external consequences of actions, attitudes, and public policies. For example, to what extent are effects of higher income on well-being based on comparisons with others in the same society? Do the benefits of living in a high-trust society depend on your own assessments, or also on more widely shared estimates? Do individuals gain satisfaction from society-wide measures of health in addition to their assessments of their own health? If the national as well as the individual values of variables are both included in the explanation of individual well-being, it is possible to show to what extent there are positive or negative spillover effects that could affect the evaluation of alternative policies. Since it is not always easy to find comparable measures at the individual and society-wide levels, and since the

estimation of two-level effects is limited by the number of countries and years for which surveys are available, this paper provides illustrations rather than definitive conclusions on the existence and size of the key national-level factors determining well-being.

\section{Previous Research}

The study of well-being has over the past century taken a distant second place to the study of psychological illness. One count places the number of psychological abstracts since 1887 mentioning anxiety as 100 times greater than those mentioning life satisfaction (Myers 2000, 56). Nevertheless there have been many studies of well-being accumulating over the years, and there is evidence of a flowering of new interest, as shown by the more than 300 articles surveyed by Diener et al (1999). The starting point of that survey of recent work is the earlier survey by Wilson (1967) of the then much more limited evidence on the constituents of happiness. Wilson's list of attributes of the typical happy person has remarkable similarities to that proposed by Aristotle, since he attributes happiness to the "young, healthy, well-educated, well-paid, extroverted, optimistic, worry-free, religious married person with high self-esteem, job morale, modest aspirations, of either sex and a wide range of intelligence." (Wilson 1967, 214).

In the subsequent thirty years, there has been a flowering of new results, using 
experiments, data samples and more complex statistical analysis to study partial effects, causal pathways and non-linearities. Experiments have shown that pleasant affect, unpleasant affect, and life satisfaction are separable constructs (Diener et al 1999, 277). Since the former two are more responsive to short-term circumstances, much of the well-being literature has focused on measures of life satisfaction. The same reasoning supports the use of a measure of life satisfaction as the dependent variable for the empirical work in this paper.

Previous well-being research has emphasized the joint importance of personality, the social environment and circumstances in determining levels of subjective well-being. Special attention has also been paid to the importance of goals and aspirations, of comparison groups, personal experience, and habituation as joint determinants of how changes in circumstances will affect individual well-being. Personality has been shown to be substantially heritable. Personality differences have been shown to affect self-assessments of well-being, and to influence how an individual responds to unfolding events. Since the data available for large-sample analysis has only limited power to identify personality types, the estimated responses to particular events will necessarily be an average across many different personality types, so that the explanatory power of equations based on individual responses is likely to be small.

Cultural and societal differences are likely to be important determinants of international differences in subjective well-being (Diener 2000). Since suitable variables and degrees of freedom are scarce, there may well remain international differences in subjective well-being that are not fully explained by available measures of individual and societal differences affecting well-being. One of the major aims of this paper will be to include both individual-level and societal variables as determinants of well-being so as to be able to estimate their separate influences on well-being.

Moving outside the psychology literature, there have been studies using measures of wellbeing in the analysis of economic and social policies. For example, Di Tella et al (2000) have used survey measures of subjective well-being to evaluate the short-term welfare trade-off 
between inflation and unemployment. They find, echoing earlier work by Clark and Oswald (1994) and Oswald (1997), that individuals rate the subjective cost of unemployment far higher than the corresponding loss of money income. They also find an apparently high subjective cost of inflation. Although inflation and unemployment are both found to be costly, relative to the well-being effects of higher incomes, the trade-off estimated from the well-being data attaches a much higher relative weight to unemployment than was implicit in the oft-used misery index ${ }^{4}$.

Broadening the scope of analysis, Frey and Stutzer $(2000,2002)$ explain differences in subjective well-being among Swiss cantons using individual variables plus measures of the direct accountability of cantonal administrations, finding that those cantons with more accountable government also show higher average measures of subjective well-being.

Putnam $(2000,2001)$ explains individual measures of well-being with individual-level and state-level variables to provide preliminary estimates of the relative contributions of income, health, social connectedness and family status to individual well-being. Some of the related literature is surveyed in Helliwell (2001a).

\section{Data and Key Variables}

This paper analyzes measures of subjective well-being drawn from three successive waves of the World Values Survey (WVS, Inglehart et al 2000). The first wave was in 1980-82, the second in 1990-91, and the third in the late 1995-97. Although each wave covers a different set of countries, there is sufficient overlap to enable some first assessments of the sources and sizes of international differences and changes in subjective well-being. There are too many changing factors to permit definitive answers, but the sample size is large enough (totalling 87,806 observations spread over three waves and forty-six different countries) to permit many of

${ }^{4}$ In the absence of grounds for any easy alternative, the 'misery index' has been defined as the sum of the percentage unemployment rate and the current annual rate of inflation. 
the relevant factors to be taken into account in a consistent manner.

The first wave of the WVS survey provides data for the current research from 18 industrial countries, all of which were members of the OECD. The 1990-91 second wave provides data from 38 countries and the 1995-97 third wave provides data for 30 countries, excluding many of the previously surveyed OECD countries. The second and third waves, especially the third, contain up to 15 countries or regions from Eastern Europe and the former Soviet Union. The changing country coverage means that there is a potential shortage of degrees of freedom for the estimation of national-level linkages simultaneously with the application of two-way fixed effects. Thus there are 49 different countries or sub-national regions represented in one of the three waves, but only 86 total country-wave observations, compared to the 147 there would have been if each country were represented in each of the three waves.

To reduce the number of country fixed-effect variables, in order to leave more degrees of freedom for the estimation of national-level effects, the countries are divided into six groups. The base group, for which no separate variable is required, includes 14 industrial countries (Australia, Austria, Belgium, Canada, France, Germany, Ireland, Italy, Netherlands, Portugal, Spain, Switzerland, UK, and US, with a special sample for Northern Ireland). The other groups include countries of the Former Soviet Union (FSU, including Russia, Ukraine, Estonia, Latvia, Lithuania, Belarus, and special samples from Moscow and the Tambov administrative region), other countries of Eastern Europe (EEUR, including Poland, Czech Republic, Slovenia, Hungary, Bulgaria, East Germany and Romania), and smaller groups of countries from Latin America (LATAM, including Argentina, Brazil, Chile, Mexico, Peru, Uruguay and Venezuela), Asia (including China, India, Japan and Taiwan), other developing countries (OTHDEV, including Nigeria, South Africa and Turkey), and Scandinavia (SCAN, including Denmark, Finland, Iceland, Norway and Sweden). Tests have confirmed that these sub-aggregates combine groups with fairly similar values for well-being, both before and after adjustment for differing values of the independent variables tested. As will be seen, the country groups differ considerably in their average levels of well-being, especially before allowance is made for international differences in 
individual and societal-level factors influencing well-being.

Table 1 (at the end of the paper) shows the means and ranges of the variables used in the main results reported in this paper. The specifics of each variable, and references to earlier research, are provided when that variable is first introduced to the analysis ${ }^{5}$. The transformations of WVS variables used to select the observations and define the variables are recorded in SPSS syntax files available on request.

\section{Results}

We start, in equation 1, with an explanation of subjective well-being based on each individual's own characteristics, leaving until equation 2 the introduction of variables relating to the society in which the individual lives. In both cases the equations are estimated by least squares, allowing for a slightly modified form of two-way fixed effects, including variables for each survey wave and for each of the country groups. Alternative functional forms and estimation procedures are considered later in the paper. The dependent variable in all equations is the individual's general satisfaction with life on a ten-point scale, with 10.0 representing the greatest satisfaction, and 1.0 the greatest dissatisfaction ${ }^{6}$.

The first independent variable considered in equation 1 is the individual's self-assessed state of health measured on a five-point scale, with 1 representing very good health and 5 very poor health. This variable is always the most significant of all of the explanatory variables. A one-point improvement in health, on the five point scale, is associated with a 0.61 point increase

${ }^{5}$ The transformations of WVS variables used to select the observations and define the variables are recorded in SPSS syntax files available on request.

${ }^{6}$ The distribution of the variable departs from normality by being left-skewed and in displaying some tendency to bunch at the middle and end points. The percentage frequencies of the ten responses, counting from 1 to 10 on the satisfaction scale, are 3.2, 2.2, 4.8, 5.4, 13.0, 10.4, 14.6, 20.7, 11.9, and 13.3. 
in subjective well-being7. Given the means and scales of the variables, a $1 \%$ increase in average reported health status is associated with just over $1 \%$ increase in subjective well-being. From the wording of the life satisfaction and health questions, this presumably reflects primarily a longterm effect, which earlier research (e.g. Brickman et al 1978) has shown to be much smaller than the short-term effect, since expectations and comparison groups adjust so as to cushion the wellbeing effects of changes in health status. Some earlier research has suggested some nonlinearities in the relation between self-assessed health status and subjective well-being, in particular that a drop from 'poor' to 'very poor' health would have a larger well-being cost than other one-point downward movements in health status. To test for this, the equation was reestimated using the central value ( $3=$ 'fair health') as the base case, with separate variables for 'very good', 'good', 'poor' and 'very poor'. The results did show higher well-being equivalents for below-average health than for above average health. Although all of the one-point differences had coefficients that were significantly different from each other, they all lie within the range 0.46 to 0.86 . In this sample of data the largest differences relate to differences between the base case and either poor health (-.856) or good health (+.622). To be in very good rather than good health adds a further 0.520 to subjective well-being, while being in very poor rather than poor health is matched by an average additional drop of 0.462). The well-being equivalent of being in very good health rather than very poor health is thus 2.46 points on the 10-point well-being scale $^{8}$. Since the other coefficients in the equation are not affected by splitting the health variable, the further analysis will make use of the simpler form adopted in equation 1.

There is reason to expect that the health coefficient in equation 1 may overstate the size

7 Holding all other individual and societal variables constant in equation 2, a disaggregation in the health variable between OECD and the rest produces almost identical results: -0.608 for OECD and -0.609 for the rest.

${ }^{8}$ This is smaller than five times the 0.61 estimated in equation 1 because the sample responses are unequally divided, with more responses in the groups with larger differences from adjacent groups. In particular, the distribution of responses among the five groups ranging from very good to very poor are $22.7 \%, 37.2 \%, 31.3 \%, 7.3 \%$ and $1.6 \%$. This may to some extent reflect a lower sampling probability for those who would self-describe themselves as being in very bad health. 
of the long-term effect of objective health status on subjective well-being, since both are affected in the same direction by personality differences. Individuals whose personalities are inherently more optimistic are more likely to give positive assessments of their health status and their subjective well-being (Okun and George 1984). Comparisons of identical twins raised together and apart (Tellegen et al 1988, Lykken and Tellegen 1996) suggest that a large fraction of longterm interpersonal differences in personality is genetic in nature. Although this fact may bias upwards estimates of the long-term linkages between health and well-being, optimism creates real linkages as well, since there is ample research showing that those who are optimistic about their health prospects, even unrealistically so, have better health outcomes than do those facing the same prognosis with a less optimistic frame of mind (e.g. Schier et al 1989).

The second independent variable relates to the individual's employed status, with unemployment represented by 1.0, with a zero value for those who are either employed or out of the labour force. Being unemployed lowers subjective well-being by as much as a one-unit drop on the five-point health scale, averaging -0.61 on the ten-point satisfaction scale. Comparisons with income and other effects will be made later, but even before that, it can be reported that these results confirm the earlier findings by Clark and Oswald (1994) and Di Tella et al (2000) that individuals report large well-being reductions from being unemployed. It is not possible to tell from these data how long the surveyed individuals have been, or expect to be, unemployed, so no attempts can be made to disentangle habituation effects, which would tend to lessen the well-being effect of long-standing unemployment, from the offsetting build-up of debt and despair, and the associated obsolescence of job-related human capital. The likely importance of habituation effects may be part of the reason why the estimated effect of unemployment on life satisfaction is significantly greater for respondents in OECD countries9.

9 The coefficients in equation 2 (individual and societal variables together) are -0.669 for OECD and -0.523 for the rest, holding all other variables constant. This is consistent with Clark (2001), which shows that the well-being effects of unemployment are smaller in those regions of the United Kingdom where average unemployment rates are higher. 
The next series of variables relate to family status. We lack information about any aspect of respondents' prior family history, including how long they have been married, separated or divorced, or whether there have been previous marriages. Thus we have nothing to contribute to the debate about whether findings of weaker correlations between well-being and marriage in some previous studies may be due to rising proportions of the now-married who are veterans of previous marriages and divorces. It is possible, however, to test whether, as some studies have indicated (Argyle 1987), marriage contributes more to the subjective well-being of men than of women. Separating the marriage effect by gender showed no difference between men and women, so that the equation reported makes no such split. The relevant literature on both debates is surveyed by Diener et al. $(1999,290)$. The results in equation 1 show a hierarchy of wellbeing, with those who are married being happiest, followed by the 'living as married', widows or widowers, the divorced, and the separated. The difference between being married and separated amounts to almost three-quarters of a point on the ten point scale, or more than being unemployed. The fact that being separated is worse than being divorced may reflect habituation and recovery effects that presumably have had more time to work for those who are currently divorced than for those who are separated. Most divorces follow separations so that the average divorced person has been either separated or divorced for longer than the average separated person has been separated.

The results for the education variables may be surprising, since education has been found to be the strongest systematic determinant of individual participation in a variety of social activities, and social connections have been linked to increased health and well-being (Putnam 2000). In equation 1 the partial effects of differing levels of education on subjective well-being are found to be small and insignificant. One explanation for this finding is that in equation 1 any beneficial effects of education flowing though higher incomes, better health, and higher perceived trust levels are already taken into account. Also it should be noted that the education variables are among the weakest in the WVS data, being based solely on the ages at which individuals finish their full-time education. This is a very imperfect guide to how much education 
has been received or what results or qualifications have been obtained. Education ages and quality also differ much from country to country, and much of the variance in the WVS sample is across countries. However, it is reasonable to conclude, in a provisional way, that in this international context those who have stayed in full-time education until a later age are not systematically more satisfied with their lives, once account has been taken of the higher incomes, wider participation and better health that might have been facilitated by their education. To confirm that education does have important indirect effects on well-being requires additional experiments, which have been undertaken and will be reported in the subsequent section.

What about age? Wilson (1967) surveyed the earlier literature, and characterized the happy person as being young. Subsequent studies have been able to separate the age linkages more systematically from those of income, health and other variables. More recent reviews (Myers and Diener 1995, Diener et al 1999) have dismissed Wilson's conclusion, and found no systematic age pattern. Perhaps because the WVS sample is so large, and health and income are separately accounted for, the WVS current results show a strong U-shaped pattern of the sort previously found by Blanchflower and Oswald (2000) for Britain and the United States, and replicated in other recent studies. The base group comprises those aged 18-24. Those in the next three age groups are significantly less happy than those aged 18-24, providing some partial support for the earlier view that life is happier for the young. However after reaching a low point among the 35-44 year-old group, subjective well-being thereafter rises systematically and significantly, with those 55 to 64 as happy as those aged 18 to 24, and those aged 65 and up much happier still. The size of the changes is large, with those over 65 having well-being more than one-half point higher (on the ten-point scale) than those 35 to 44 , a difference almost as great as that between the employed and unemployed.10

Earlier research has found a strong correlation between measures of religious activity and

10 The age coefficients for OECD are: $25-34:-0.224,35-44:-0.383,-0.368,45-54:-$ $0.368,55-64:-0.126,65+: 0.267$. The corresponding coefficients for the rest of the sample are: 25-34: -0.168, 35-44: -0.324, 45-54: -0.305, 55-64: - 0.0774, 65+: 0.06341. The general pattern is the same in the two groups of countries, but old age is more satisfying in the OECD countries. 
subjective well-being. There has been some debate as to whether this is due to the support provided by religious beliefs and convictions or to the social and community networks provided by regular participation in church activities. The WVS data permit these two channels to be separately evaluated, since respondents are asked about the importance of God to their lives as well as how frequently they attend church. The results show that both variables have strong and easily distinguished linkages to life satisfaction. Those who report that God is very important to their lives (33\% of the sample) have life satisfaction measures higher by 0.34 , with the effect of weekly or more frequent church attendance ( $22 \%$ of the sample) also being significant, although only one-third as large ${ }^{11}$. Tests of differences of these effects among religious faiths show that they apply across all major faiths.

As a prelude to consideration of variables relating to measures of the quality of national institutions, equation 1 considers individual assessments of some key elements of each nation's social capital. There are two variables relating to each individual's own participation in voluntary organizations of all types except church groups, since church affiliation and participation is covered by a separate variable. One variable (MEM12) covers the first two waves of the survey, while the other relates to the third wave (MEM3). Two variables are used because the voluntary associations question was asked differently in the third wave, producing significantly higher average participation rates (Inglehart et al. 2000). The different average participation rate in the third wave will also be responsible for part of the coefficient on the fixed effect for the third wave. The coefficients on both membership variables show that individuals who are involved in more voluntary associations report higher average satisfaction with their lives. The variable measures the total number of membership types for each respondent. The

11 The simple correlation between the two variables is 0.40 . Of the roughly 29,000 for whom God is very important, fewer than half go to church one or more times per week. Of the 20,000 who go to church at least once per week, two-thirds report that God is very important to their lives. 
coefficient on the variable for the first two waves suggests that someone with an additional voluntary group membership, with an average degree of involvement, has well-being that is higher by 0.05 , about a tenth as much as marriage. The number is estimated to be twice as large in the third wave. Since optimistic individuals are more likely to report themselves satisfied with life, and to assume the best from new ventures, they are probably also more likely to join and participate in voluntary associations. Thus the positive partial correlation between individual memberships and well-being may reflect in part the common influence of personality differences, just as was argued above for physical health. However, it will be shown later that societies with high averages of social capital, as measured by membership densities, also show higher levels of subjective well-being, other things held constant. This relation cannot be readily attributed to personality differences amongst individuals, since these average out at the national level.

The "NOCHEAT" variable takes the value of 1.0 for every individual who thinks that it is never justifiable to cheat on taxes. As shown in Table 1, slightly more than half of the respondents think that cheating on taxes is never justifiable, and equation 1 shows that they systematically report themselves more satisfied with their lives. The same is true for those who reply 'yes' when asked if they think that, in general, people can be trusted, rather than the alternative that you cannot be too careful when dealing with people. It is tempting to treat this positive effect of trust assessments as representing the well-recognized individual benefits of living in a high-trust society. However, it cannot be only that, as equation 2 will show shortly that the coefficient on individual differences in trust assessments remains unchanged even after national differences in trustworthiness are taken into account separately.

Perhaps this is one more instance where optimism produces higher assessments of both trust and well-being. An alternative view is that individuals differ in their sub-national communities, and their answers relate to the run of people with whom they interact, and not to the nation as a whole. This alternative view would permit the interpretation of the positive effect as representing the benefits of living in a high-trust community, assuming that most of the interpersonal differences in trust assessments represented differences among communities in the 
same nation in the average level of trustworthy behaviour.

Earlier studies and surveys of the literature on the effects of income on subjective wellbeing provide an ambiguous picture. For samples of data including individuals within the same country, those with higher relative incomes generally ${ }^{12}$ show significantly higher measures of subjective well-being, although the magnitude of the effect is often described as small (Diener et al 1999, 287). It has also been noted that big increases in individual income or wealth, such as those provided by a large lottery win, show well-being effects that are positive but declining with time to fairly small residual levels (Smith and Razell 1975, Brickman et al 1978). Simple crosscountry correlations of GDP per capita and measures of subjective well-being show a significant positive correlation (Myers and Diener 1995, 13), but countries with faster-growing GDP per capita have not shown corresponding increases in well-being (Easterlin 1974, 1995, Myers and Diener 1995, 13, Oswald 1997). In some countries there is evidence of increasing prevalence of materialistic goals among the young (Astin, Korn and Riggs 1993), which might be thought to lead to larger or more significant higher well-being effects from higher incomes. However, other studies found that individuals attaching high subjective values to financial success have lower values for subjective well-being, even when their financial aspirations were met. (Kasser and Ryan 1993, 1996).

The WVS data offer some advantages and some disadvantages in identifying the linkages between income and well-being. The advantages flow from the very large sample size, and the inclusion of countries and individuals with very different levels of income. The disadvantages relate to the difficulties of comparing relative incomes among countries and among individuals. To compare incomes across countries, we use real GDP per capita, measured at purchasing power parities, in the year of the survey, making use of the Penn World Tables, as updated in the

${ }^{12}$ But Clark and Oswald (1994) do not find a significant effect in their sample of UK data. 
World Bank growth dataset. To capture individual incomes, the WVS asks respondents to place their family incomes on a ten-point scale, where the ranges they are offered are supposed to be based on the family income deciles in that country and year.

Theory and some previous research suggest that the effects of individual and national incomes may be non-linear in nature, with smaller well-being effects attached to increases in income beyond levels sets by each individual's or society's expectations and habits (Offer 2000). Habituation effects are hard to establish with the WVS data, since there is no way to tell how the family incomes reported relate to recent or normal levels. To search for non-linearity of the individual relative income variable, the equation includes the decile value (where the range is from .1 to 1 , and the mean is 0.5 ) and the decile value squared. In equation 1 , both take significant coefficients, with signs that imply diminishing returns to higher relative incomes. For an individual to move from the fourth to the fifth decile in the distribution of family incomes raises well-being by $+0.10\left(=1.91 * .1-.96^{*} .09\right)$, while to move from the ninth to the tenth decile is associated with an increase in well-being of only $0.01\left(=1.91 * .1-.96^{*} .19\right)$. This is despite the fact that for most countries the move from the ninth to the tenth decile involves a much larger absolute and relative increase in income than to move from the fourth to the fifth decile. Thus there are sharply decreasing well-being effects from higher incomes relative to those elsewhere in the same country ${ }^{13}$

${ }^{13}$ The situation is more complicated if one uses separate variables for each income decile, with the lowest decile as a base case. The changes to subjective well-being from each of the nine steps from the second to the tenth decile (with the basis for comparison being respondents in the lowest decile) are $+.091,+.190,+.138,+.113,+.024,+.125,+.015,-.012$, and +.090 . The general pattern of declining increments is apparent, but there is some evidence of additional sense of well-being from being in the top decile, which represents in many countries a substantial increase in income from the deciles immediately below. Subsequent work has established a clear distinction between the effects of relative income in the OECD and in the developing countries. For the poorer countries, there continue to be significant increases in subjective well-being from increases in relative income throughout the ten deciles, while for OECD countries, the increases in well-being with income are concentrated in the first four deciles, with no significant increases in subjective well-being beyond that point (holding constant all other variables, of course). When the effects are estimated separately for OECD and non-OECD countries, they are: OECD: 0.0325 (not significant), +0.00179 (not significant), $+0.124,+0.208,+0.195,+0.243,+0.232$, 
To extend the analysis internationally, and to try to disentangle the statistical effects of absolute income levels from those of domestic and international relative incomes, it is necessary to make the first addition of national variables, as reported in equation 2. Adding several national variables alters the size and significance of the individual variables surprisingly little, even where, as in the case of trust, the national value being used is the national average of the corresponding individual variable.

The addition of variables describing the structure of the national society raises the explained variance from $25.5 \%$ to $26.3 \%$ if the regional and time variables are in the equations, or from $15 \%$ to $25.6 \%$ if they are not. Comparing the regional variables and the national societal variables as means of explaining the variation in well-being not explained by individual factors, the national variables are collectively slightly more powerful (25.6\% of variance explained by the national variables compared to $25.5 \%$ for the time and regional variables, with individual-level variables included in both cases). The national societal variables and the regional variables are partly substitutes and partly complements, in that both remain highly significant in equation 2 which contains both. Our main interpretation will centre on equation 2 rather than on equation 1 , which excludes regional effects. This is a not matter of much consequence, as comparison of the two equations show that the inclusion of regional effects does not generally change the coefficients on the societal variables. The main exceptions are those for education, due to low well-being and high education levels in the FSU and Eastern European countries. Thus although it is clear that there is ample scope to find new explanations for the remaining regional effects, the current societal variables are not achieving their success merely as back-door ways of capturing regional differences based on other factors. However, subsequent robustness checks suggest that attempts to increase the number of country dummy variables, or to change the numbers and natures of the country groupings, do have material effects on some of the contextual variables. This is because of the relatively small number of observations of the national

$+0.223,+0.333$. REST: $+0.158,+0.445,+0.584,+0.716,+0.771,+0.976,+1.071,+1.142$, +1.254 . 
variables- often as little as one per country - so that the power of the equation to identify the effects of national variables is seriously affected by inclusion of larger numbers of country variables. This suggests caution in interpretation of the sizes on some of the national variables, and puts a premium on extending the data sample to include the millennial round of the World Values Survey. In addition, the standard errors reported in equation 2 assume independence of individual error terms within national samples. Allowing for with-country error correlations, as is done later in the paper, raises the standard errors on the societal-level effects, and leads to a corresponding reduction in the number of national level effects that can be separated to a high degree of statistical significance.

Now that equation 2 has been introduced, we can return to the consideration of individual and national income effects. The national income per capita variable is scaled by showing each country's average relative to the value for 1997 in the United States. The logarithm and the square of this variable are then included, and both attract highly significant coefficients. This pair of variables is strongly preferred by the data to simply the level and the square, or to any of the three variables on their own. We find that national average income also has diminishing returns, since the logarithm of average per capita income takes a positive coefficient, while the square takes a negative coefficient. Use of dummy variables for each decile of the international distribution of national average per capita incomes shows evidence of a double hump, with local peaks about one-third and two-thirds of the way up the national income ladder. However, the use of decile data reduces excessively the number of degrees of freedom available to identify significant national income and other national-level effects. Grouping of deciles will be used later in the paper to address this issue. It is much easier to use individual deciles to establish relative income effects within each country, because the sample sizes are large enough to identify fairly stable and very significant patterns, and to establish different patterns for the OECD and developing countries. A fresh round of data from the larger end-of-century WVS survey should help to better establish the cross-sectional and time series effects of differences in average incomes. 
The next societal variable to be added is the average level of interpersonal trust. This is as estimated by the national average answer to the question: "In general, do you think that people can be trusted, or alternatively, that you can't be too careful when dealing with people? " (2001) has shown that international differences in sample average responses to this question are good predictors of international differences in the proportion of experimentally dropped moneyfilled wallets that are returned with their contents intact. Hence average individual assessments of the extent to which people in general can be trusted mirror at least some key aspects of the trustworthiness of their fellow citizens. It would be useful to have more specific information about the radius of trust people assume when answering the question. The Knack (2001) finding suggests that people are responding to their experience in and knowledge of their own national societies, although there may well be admixtures of more local and more international experience being taken into account.

Equation 2 shows that differences in national average trust over time and across countries have a large and significant effect on subjective well-being. This does not flow from a false relation linking optimism with assessments of general trustworthiness and of personal wellbeing, since the equation also includes the individual's own estimate to which others can be trusted. Hence the coefficient on the national trust variable has some claim to reflect the average perceived benefits to individuals of living in an environment where other people can be trusted. The coefficient of 0.32 implies that average well-being would increase by .03 on a ten-point scale for each 0.1 increase in the proportion of the population judging that people can in general be trusted. A difference of 0.1 in average trust levels is less than the sample standard deviation of 0.14 , and less than one-third of the difference between trust levels in France and Norway, a comparison used by Grjebine (2000) and Helliwell (2001a) in the analysis of international

14 This way of asking the trust question was used by Almond and Verba (1963) in their pioneering study of democracy, and has been the main basis for comparative research for more than forty years. 
differences in traffic behaviour and road fatalities.

The next societal variable is based on a large World Bank effort to collect and analyze measures of the quality of governance for more than 150 countries in the 1990s. The authors (Kaufmann, Kraay, and Zoido-Lobatoni 1999a, 1999b) summarize and interpolate data collected by others for an average of more than 25 different indicators of the quality of governance, divided into six separate aspects: voice and accountability, stability and lack of violence, government effectiveness, the regulatory framework, the rule of law, and the control of corruption. For each group of indicators, the measures are scaled to have a mean of zero across all of the countries included, and a range from +2.5 to -2.5 . An aggregate formed by summing the five measures to a single index of the quality of governance (GOVTOT) has a mean of 0.65 for the countries represented in the WVS data, and ranges from 1.72 for Switzerland at the top to 1.00 for Nigeria at the bottom. There are many reasons why higher values for such a variable would be associated with higher average levels of subjective well-being. Many services crucial to individuals and families, ranging from education and health to justice and transportation, are regulated and provided by governments. The quality of the services received, for any given amount of resources expended, is likely to be higher where the overall quality of government is higher. Perhaps more important, the confidence with which individuals face their future is likely to depend considerably on the confidence with which they can rely on government services being available when and where they are needed.

The coefficient of $.32(\mathrm{t}=12.0)$ on the GOVTOT variable implies substantial well-being benefits from improvements in the quality of governance. For example, an improvement in the quality of government in Belarus (-.76) to that of Hungary (+.87) would (if the relation were causal) increase the average well-being of a citizen of Belarus by more than marriage, by about as much as the combined effect of religious belief and church attendance, and almost as much as moving from the bottom to the top decile in the country's income distribution.

Two societal variables were considered for physical health- the infant mortality rate and 
the average life expectancy. Life expectancy had no significant effect. An earlier version of this paper identified a significant effect of the infant mortality rate, which was eventually found to have the wrong sign, and in any event be due for its significance to entirely to one country (Japan) which had the lowest infant mortality rate (4.3 per 10,000, compared to 7.1 per 10,000 in the United States, and a high of 81.1 in Nigeria), and also with subjective well-being lower than its circumstances would otherwise have suggested. More research is required to gather better societal level measures of averages levels and distribution of states of physical health. When the next round of WVS data becomes available, there will be more degrees of freedom to identify different patterns of national and possible even sub-national level contextual effects.

\section{Social Capital, Education and Well-Being}

It has already been shown that the national values of the trust variable have systematic positive effects on well-being, reflecting some of the benefits flowing to individuals living in societies where trust replaces suspicion and fear. These direct benefits on well-being are in addition to those that may flow through greater efficiency in economic affairs and government, since these channels are already directly modelled. Higher values of trust are often thought of as one of the main channels through which increases in the right types of social capital improve economic and social well-being. Sometimes measures of trust are included as part of what is meant by social capital, although there is some evidence of emerging consensus to treat trust as an immediate consequence of the right types of social capital, where the latter is more narrowly defined, for example to include "networks together with shared norms, values and understandings which facilitate co-operation within or among groups" (OECD 2001). We are now in a position to see if increases in the national density or quality of these norms and networks increase individual well-being beyond the widely-recognized benefits of individual participation, and in addition to the effects flowing through higher national average values of trust.

A first fairly obvious norm to consider is whether the members of a society readily agree to pay their allotted shares of the costs of their collective actions. A natural measure for this is the 
national average fraction of respondents who think that it is never appropriate to cheat on their taxes. We have already seen that individuals who think that cheating on taxes is wrong have higher subjective well-being. Now we are in a position to see if their well-being is systematically higher if they live in a society in which people generally think that it is wrong to cheat on taxes. The coefficient on the national average measure (NOCHEATN) is $0.26(\mathrm{t}=4.3)$, implying significant further benefits to shared high standards for communal responsibility. Adding the national variable only slightly reduces the coefficient on the individual's own opinion of tax cheating. The sum of the two coefficients is almost 0.5 , suggesting that the benefits of a widely supported set of tax rules go beyond direct savings in collection and enforcement costs. People who cheat appear to be less happy. Widespread acceptance of cheating lowers average satisfaction, whatever one's own willingness to condone cheating.

We have already seen that those who are more connected, whether through participation in churches or other voluntary organizations, are more satisfied with their lives. What remains now to be seen is whether their participation makes others better off as well. To assess this possibility, equation 2 includes national average levels of the weekly-or-more church attendance variable, and national average memberships in other voluntary associations. As already noted, the other memberships question took a different form in the third wave of the WVS, and elicited higher average responses, so that separate variables are used for the third wave. The results suggest that on average the benefits of high church attendance flow mainly to the church goers themselves, since the variable takes a smaller coefficient than is attracted by the variable for other memberships. Both variables for other memberships take significant positive coefficients. The evidence from all types of memberships suggests that there are positive spillovers to the well-being of others. Previous research did not find any such spillovers from memberships to economic growth (e.g. Knack and Keefer 1997, Helliwell 1996a, Knack 2001), and in any event income levels are already accounted for in equation 2, so the national membership effects in equation 2 would seem to flow directly to well-being rather than through income or trust. The estimated effects are large and significant. If everyone joined one additional group, the resulting increase in well-being would exceed that from marriage. Using the third wave coefficients, for 
example, the average well-being would increase by .06 from the individual effect and .58 from the national effect, for a total effect of 0.64 . Of course, such an increase would be historically unprecedented, and represents a larger difference than that between the most and least horizontally connected of the national societies included in the data. The most important feature of these results is that the spillover effects on the well-being of others are estimated to be substantially larger than the direct benefits, even after taking into account any benefits that may have flowed through higher trust or higher incomes.

Turning to education, equation 2 includes a measure of the average educational attainment in each society, measured in completed years. The data are based on the de la Fuente and Donénech (2000) estimates for the OECD countries and the Barro and Lee (1996) estimates for other countries. The two sources should be consistent, since the OECD data are intended to improve on the Barro and Lee data for the OECD countries while keeping the same basic methodology. Their data for 1980 are used for the first wave of the WVS, and their 1990 estimates are used for both waves in the $1990 \mathrm{~s}$, in the absence of more recent data ${ }^{15}$. The national attainment data show no net impact on well-being.

How can these neutral results for the partial effects of own and national education be squared with earlier research (e.g. Wilson 1967) suggesting that the typical happy person is welleducated? To see if there is a conflict, equation 3 replicates the sort of direct estimate that was frequently employed in early studies. The equation simply adds the individual and national education attainment variables to the most basic equation including only time and regional fixed effects. The results are quite striking. One's own education has a strong positive effect on wellbeing, and the strong positive effect from the national average variable indicates the existence of positive spillovers to others. Equation 4 adds the full set of individual determinants of well-

${ }^{15}$ Alternative measures based on secondary and tertiary enrolment rates, and their average, were also assessed, and proved empirically weaker. The attainment data are in any case theoretically preferable, since average well-being should depend on average attainment, and not on the current pace of educational investment. 
being. The individual education effects are largely removed, while the national spillovers remain strongly significant. Only when the other national variables are included, as in equation 2, do the spillover effects of education disappear. The inference to be drawn is presumably that the individual well-being benefits of education flow primarily through their well-documented effects on participation, health, perceived trust, and higher incomes ${ }^{16}$. In a parallel way, the beneficial spillovers apparent from equations 3 and 4 are fully captured by the channels captured by the national norms and networks variables ${ }^{17}$. Thus these results suggest once more the importance of separating direct and indirect influences, and making conclusions conditional on particular sets of other variables and channels of influence. The well-documented benefits of education appear to flow less through a direct impact on life satisfaction than through its positive effects on the creation and maintenance of human and social capital ${ }^{18}$.

Other variables assessed but not used in equation 2 include a measure of nationwide income inequality and a simple variable designed to capture generational effects ${ }^{19}$. There is some cross-section evidence that increased income inequality is associated with lower rates of economic growth (Persson and Tabellini 1994), and worse health outcomes ${ }^{20}$. Equation 2 would

${ }^{16}$ Tests show that the individual variables for income, health, memberships, trust and tax cheating all played a role in reducing the positive effect of one's own education. On the effects of education, social capital and other aspects of socioeconomic status on health, see Wolfe and Haveman (2001) and Michalos et al (2000).

17 Tests show that the national variables for trust and quality of government were the biggest contributors to reducing the coefficient on national educational attainment.

${ }^{18}$ See OECD (2001) for a survey of the evidence.

${ }^{19}$ The generational variable was a variable that took the value 1.0 for each respondent born prior to 1950. Putnam $(1995,2000)$ has found that in the United States those who were born prior to 1950 show significantly higher community involvement and trust. Such effects may be captured in equation 2 by the inclusion of the membership and trust variables. However, the generational variable did not contribute directly to the international well-being equation whether or not the trust and membership variables were included.

${ }^{20}$ On the effects of income inequality and social capital on health outcomes, see Wilkinson (1992), Kawachi et al (1997), Ben-Shlomo et al (1996), Gravelle (1998), Wolfson et 
capture these effects through the health status and income variables. Adding a World Bank estimate of the Gini coefficient for each national economy added no explanatory power to the well-being equation. There are, however, some well-being effects of income inequality implied by the non-linear way in which personal and national average incomes enter the well-being equation. Because the quadratic terms are negative both for the decile position of individuals and the average national income, an economy with a more equal distribution of income will achieve a higher average level of well-being, for any given level of average per capita incomes. The size of these effects depends on the functional forms being used, and may well differ by country (Alesina 2001). More tests and perhaps better data are required to permit more confident conclusions.

Finally, a word about the remaining regional effects, which in equation 2 are still substantially negative for the countries of the former Soviet Union, with a negative effect almost half as large for the countries of Eastern Europe. Subsequent tests, reported in the next section, show that this simple average hides important changes over time. In 1990 the negative residuals are equally large in the FSU and Eastern Europe, between 1990 and the mid-1990s survey they grow even larger for the FSU and largely disappear in Eastern Europe. The three Baltic countries have been included in the FSU variable, although their experience before, during and since their time as parts of the Soviet Union is very different from that of other republics. However, tests show the coefficient for the Baltics to be similar to that for the rest of the FSU. There are significant positive regional effects in Latin America and Scandinavia, and negative effects in Asia and the Other Developing category. It is interesting to compare these post-modelling residual regional effects with what would be implied by the basic data. If an equation is run including only the regional and time fixed effects, the negative regional effects in the FSU and Eastern Europe are far larger, at $-2.34(\mathrm{t}=99)$ and $-1.20(\mathrm{t}=43)$, as are those in Asia $(-.502, \mathrm{t}=18)$ and for other developing countries $(-.686, \mathrm{t}=22)$. The Scandinavian positive effect in the simple regression is much higher in the simple equation $(+.612, \mathrm{t}=23)$, while that for Latin America is -

al (1999), and Rose (2000). 
$.173(\mathrm{t}=6)$.

Adjusting for the international differences in personal and especially national variables has the effect of sharply reducing the otherwise unexplained regional effects, and of shifting the Latin American effect from negative to positive. In all cases the comparisons are with the remaining OECD countries. This implies that relative to the main body of OECD countries, the key explanatory variables are less favourable in all of the developing regions, and especially in the FSU and Eastern Europe, than in the OECD. The reverse is true for the Scandinavian countries, which have more beneficial values for most variables than is the case elsewhere in the OECD. Even after allowing for these effects, self-assessments of well-being in Scandinavia remain higher than elsewhere in the OECD. In Latin America, even though self-assessed wellbeing is lower than in OECD countries, the differential is less than our model would predict, so that when the full model is applied the surveyed Latin Americans are more satisfied with their lives than their circumstances would suggest.

\section{Robust Estimation of a Revised Equation}

In some respects, the results in equation 2 seem too good to be true, showing independently significant effects of a wide range of individual and national effects. With respect to the national effects, such scepticism is justified. The least squares estimation adopted for equation 2 assumes that each observation is drawn from the same distribution, thus providing a very large number of degrees of freedom. However, there are no doubt systematic differences among countries in the error terms as well as in the key variables used in the equation. Thus it is appropriate to adopt an estimation strategy that calculates robust standard errors recognizing the correlation of error terms among respondents in the same country (Moulton 1990). This has the effect of reducing to about 50 the number of independent observations available for estimating the effects of national variables. This does not change the values of the coefficients, but does increase, almost threefold, the standards errors on the national variables. This increase in standard errors removes some of what previously were significant differences among sub-groups, and suggests a slimmer specification of key national variables. 
Equation 5 shows the results of re-estimating the full model with robust standard errors. This equation also embodies several of the insights that were discovered through the various specification tests that have already been described in the text and footnotes. The final equation also makes further refinements to the estimation strategy, by using an ordered probit in place of the linear model employed for equation 2, and allows appropriately for the differing sampling weights in each country survey. The probit form is more general than the linear form, since it does not have to assume that each move from one level to the next of the life-satisfaction index has the same importance to the individual. However, the differences between cut-lines, shown below the equation, are of roughly equal size, suggesting that the linear assumption was not seriously incorrect. Thus the results do not depend importantly on whether the measures of subjective well-being are treated as ordinal or cardinal. The cut-line results also provide a handy metric to interpret the size of the coefficients in the probit equation. Dividing each coefficient by the average distance between cut-lines provides coefficients comparable to those in the earlier equations. Roughly speaking, this involves slightly more than doubling the coefficients in equation 5. Thus most of the key individual effects remain the same as in equation 2. Based on earlier tests, the effects of unemployment on well-being are now estimated separately for OECD and non-OECD residents. They are highly significant in both groups of countries, but are significantly higher in the OECD. The effects are relative income are now shown in much more detail, and separately for OECD and other countries. The bottom three deciles in the OECD, and the bottom 2 in the rest of the countries are combined, because they are not significantly different. As noted earlier in the paper, increases in individual incomes, relative to others in the same country, are matched by continuing increases in subjective well-being in the poorer countries, but not in the OECD countries, where average incomes are much higher.

Equation 5 includes only those national variables for which the coefficients remain significant with the revised estimation techniques, plus three variables covering groups of countries with different levels of national income per capita. The significant variables relate to 
the overall quality of government 21 and the average number of memberships. Since the difference between the membership effects is not significantly different between survey waves, a single effect is estimated, which is slightly larger than was the average effect in equation 2 , after allowing for the difference in the functional form of the equations. The national income effects are now estimated by splitting the countries into four groups, with the base category being countries with real per capita GDP less then 20 percent of that in the United States in 1996. Separate coefficients are then estimated for the additional well-being for those in countries with 20 to $50 \%$ of US per capita GDP, 50 to $75 \%$, and over $75 \%$. As can be seen, the well-being effects of living in higher income countries are small and insignificant, and do not show any evidence of subsequent increase once GDP per capita exceeds half that in the United States in the mid 1990s. Yet it remains the case that on average, subjective well-being is much higher in OECD than in non-OECD countries, and the OECD countries are also much richer. Why this apparent paradox? The reasoning is the similar to that in the case of education. A reduced-form equation shows that subjective well-being is higher in the richer countries, but both education and income effects fall out in the full model, which includes health, social connections, and the quality of government, all of which are higher in the richer countries22. Those who have the

21 Consideration was also given a variable that takes the value of 1.0 for each respondent who thinks that 'most or all public officials (in the country) are engaged in bribe-taking and corruption.' This is perhaps the best individual-level assessment of governmental quality available from the WVS survey data, and shows systematically higher subjective well-being among those who do not view their governments as corrupt. There is a strongly significant correlation between this individual-level measure and the aggregate measure of governmental quality. Including the individual-level view of corruption does not drive out the aggregate variable, which remains highly significant even with the revised estimation methods. However, the final version of equation 5 leaves out this variable, since the question was not asked in all countries and in all waves, so that its inclusion could bias the residual estimates of country and region effects. The coefficient on corrupt was $-.08(\mathrm{t}=5.8)$, with most other coefficients unchanged to 3 or 4 significant figures.

22 To be more specific, when only the three average income variables are included in a linear equation with robust standard errors, the well-being effects grow with each income group, being $+1.01(\mathrm{t}=3.0)$ for $\mathrm{y} 2050$ (relative to countries with y less than $20 \%$ of that in the United States), $1.61(\mathrm{t}=4.8)$ for $\mathrm{y} 5075$, and $1.87(\mathrm{t}=5.5)$ for yover75. Adding govtot to the equation cuts these effects in half, and renders them insignificant. Adding health status makes the income effects start to fall after the middle income range is reached. If average education and the income variables are used in alternative equations, the education variable is stronger than the income 
highest levels of subjective well-being are not those who live in the richest countries, but those who live where social and political institutions are effect, where mutual trust is high, and corruption is low.

Equation 5 also re-estimates the specific regional effects, which reflect international differences in subjective well-being that remain significant even after allowing for all of the model's explanatory variables and the new methods of estimating standard errors. Scandinavia remains a significant positive outlier. Following the tests reported earlier, the effects for Eastern Europe and the Former Soviet Union have been split by time period. In 1990, subjective wellbeing was abnormally low in both regions, by even more in Eastern Europe than in the FSU. By the mid-1990s, however, things had got even worse in the FSU, even relative to the declining circumstances, but there was no significant negative residual in Eastern Europe. This pattern is revealed strongly by the coefficients reported in Equation 5. Regional effects for other groups of countries are no longer significant with robust standard errors, and are therefore not present in equation 5 .

\section{Conclusions and Prospects}

This paper has attempted to illustrate rather than exhaust the possibilities for using international well-being data to measure and explain differences in well-being within and among nations. International well-being data permit the combined use of individual and societal variables. This in turn makes it possible to identify the consequences of societal or ecological variables, whether they be the consequences of history, government policy, or community choices. The well-being data themselves have fairly good claims as measures of individual welfare. Insofar as these claims are justified, the coefficients can be used to combine what might otherwise be incommensurable results into an overall welfare assessment of changes in policies or institutions.

variable if the equation also includes the FSU and Eastern Europe effects. National education does not perform so well in a simple equation without the FSU effects, since well-being is 
The use of well-being studies for the comparison of societies and the evaluation of alternative policies is still in its infancy. The firmest recommendation is thus for better data and more research. Some researchers of well-being have argued that it is not too soon to think of constructing national well-being indexes to supplement and improve the available measures used for cross-national comparisons (Diener 2000). In a sense, this is what the United Nations Development Programme (UNDP) has already done with its measures of the quality of life, and what others have done to develop broader measures of economic well-being (Osberg and Sharpe 2001). The availability of large samples of well-being data offers the prospect of much stronger empirical grounding for attempts to devise measures and comparisons of well-being, and to compare alternative policies intended to improve well-being.

One of the particular branches of social science that has much to gain from systematic use of well-being data is the study of the causes and consequences of social capital. The widespread interest among social scientists and policy-makers in social capital has much to do with influential studies, especially those of Putnam $(1995,2000)$ that have shown sharp falls in trust and participation over the past forty years in the United States, following a period of rapid rise over the first sixty years of the twentieth century. The final decades of the twentieth century have also seen rapid economic growth and greater inequality of income distribution in the United States. Are these economic and social trends connected? If so, then how, and how can they be jointly assessed?

especially low there, and education levels high. 
The last decade of the past century started with the fall of the Berlin Wall. This led to rapidly increased openness in the countries formerly behind the iron curtain. The fall of the Wall was thought at the time to presage, with good luck and help from others, fairly rapid convergence of economic and social conditions towards those in Western Europe (Marer and Zecchini 1991). But in the succeeding decade, as the WVS and other data document starkly, things have gone from bad to worse in many of the countries involved, and even in the luckiest and likeliest countries the standards of material and overall well-being are now barely matching what they were in 199023.

Both of these striking pieces of history invite attempts to assess their causes and consequences, and to explain the extent to which they arise from common causes. Analysis of well-being data provides means for combining income, employment, governmental effectiveness, family structure and social relations together in ways that permit the external effects of institutions and public policies to be assessed. To provide a specific example, many earlier studies of the importance and quality of national legal systems and governance in general have emphasized only the effects that flow through economic growth (e.g. Mauro 1995, Helliwell 1996a, Knack and Keefer 1997, Knack 2001). The well-being data show that the effects flowing directly from the quality of the institutions may dwarf those that flow through productivity and economic growth. Putnam (2001) provides an insightful example of how well-being data can be used to compare the effects of income, education and social capital, using both individual-level and state-level variables to help identify spillover effects at the state level. His example provided impetus for this paper's application of a similar method to international comparisons of national data.

23 For example, the 1999 Annual Report of the European Bank for Reconstruction and Development estimated that of the 25 former East Bloc countries monitored by the EBRD, only Poland and Slovenia had by 1998 regained their 1989 levels of real GDP, while the levels of real GDP in Russia and Ukraine in 1998 were only 55\% and 37\%, respectively, of what they had been in 1989. 
There are many ways in which the preliminary research reported here invites further tests and extensions. One feature missing entirely from this paper is consideration of the extent to which geography matters. The paper has made use of regional variables, for example, on the assumption (supported by the data) that well-being moves in similar ways in at least some groups of neighbouring countries. The paper has made even more use of national variables, assuming, with some justification but not much testing, that national borders do indeed define the edges where societal cleavages are most abrupt. The WVS data do contain sub-national regions, so that it should be possible to test more extensively whether intra-national well-being linkages are tighter than those across national borders, much as has already been done for trade, capital, and migration linkages ${ }^{24}$.

Finally, it is important to re-emphasize that in many cases the methodology used in this and earlier studies can establish linkages or correlations but not prove the existence or direction of causation. It is especially important to remember this caution when considering policy initiatives that might help or hinder some type of activity that research has linked to measures of well-being. Unless the causal chain does indeed run from the activity to well-being, the policy change may not have the intended effects. Even if the chain does run in the intended direction, a change in activity level that arises from the policy change may have different consequences from

${ }^{24}$ McCallum (1995) discovered that trade linkages were twenty times tighter among Canadian provinces than between Canadian provinces and US states. Helliwell $(1998,2000)$ reports a broader range of evidence, covering many more countries, also suggesting that national borders still mark much more important boundaries in economic and social space than is generally believed. Keller (2000) shows that geography and borders both matter for technological spillovers. Helliwell (1996b) makes a preliminary attempt to combine sub-national and international data for social capital. 
previous changes that arose for other reasons. Thus well-being research does not yet provide a complete guide to choices for private behaviour and public policies. It does enrich substantially the scope for considering the well-being consequences of a broad range of disparate trends, and for using international evidence to illuminate national trends and issues.

\section{References}

Almond, Gabriel A., and Sidney Verba (1963) The Civic Culture: Political Attitudes and Democracy in Five Nations (Princeton: Princeton University Press).

Annas, Julia (1993) The Morality of Happiness. (Oxford: Oxford University Press).

Argyle, Michael (1987) The Psychology of Happiness. (London: Methuen).

Argyle, Michael (1996) "Subjective Well-Being." In Avner Offer, ed. In Pursuit of the Quality of Life (Oxford: Oxford University Press) 18-45.

Astin, A.W., W.S. Korn and E.R. Riggs (1993) The American Freshman: National Norms for Fall 1993. (Los Angeles: UCLA Graduate School of Education).

Barnes, Jonathan (1984) The Complete Works of Aristotle. (Princeton: Princeton University Press)

Barro, Robert and Jong-Wha Lee (1996) "International Measures of Schooling Years and Schooling Quality.” American Economic Review Papers and Proceedings 86(2): 21823.

Ben-Shlomo, Y., I.R. White, and M.G. Marmot (1996) "Does the Variation in Socioeconomic Characteristics of an Area Affect Mortality?" British Medical Journal 312: 1013-4.

Berkman, L.F. and S.L. Syme (1979) "Social Networks, Host Resistance, and Mortality: A NineYear Follow-Up Study of Almeda County Residents." American Journal of Epidemiology 109: 186-204.

Blanchflower, David G. and Andrew J. Oswald (2000) "Well-Being Over Time in Britain and the USA." NBER Working Paper No. 7487. (Cambridge: National Bureau of Economic Research).

Brickman. Philip, Dan Coates and Ronnie Janoff-Bulman (1978) "Lottery Winners and Accident Victims: Is Happiness Relative?” Journal of Personality and Social Psychology 36(8): 
917-27.

Brunstein, J.C., O.C. Schultheis and R. Grassman (1998) "Personal Goals and Emotional WellBeing: The Moderating Role of Motive Dispositions." Journal of Personality and Social Psychology 75: 494-508.

Clark, Andrew (2001) "Unemployment as a Social Norm: Psychological Evidence from Panel Data." (Document No. 2001-17, DELTA, available at www.delta.ens.fr )(Forthcoming, Journal of Labour Economics)

Clark, A.E. and A.J. Oswald (1994) "Unhappiness and Unemployment.” Economic Journal 104: 648-59.

De la Fuente, Angel, and Rafael Donénech (2000) "Human Capital in Growth Regressions: How Much Difference Does Data Quality Make?" Economics Department Working Papers No 262 (Paris: Organisation for Economic Co-operation and Development)

Diener, Ed (2000) "Subjective Well-Being: The Science of Happiness and a Proposal for a National Index.” American Psychologist 55(1): 34-43.

Diener, E., E.M. Suh, R.E. Lucas and H.L Smith (1999) "Subjective Well-Being: Three Decades of Progress." Psychological Bulletin 125(2): 276-302.

Di Tella, R., R.J. MacCulloch and A.J. Oswald (2000) "Preferences Over Inflation and Unemployment: Evidence From Surveys of Happiness.” (Working Paper)

Easterlin, R. A. (1974) "Does Economic Growth Improve the Human Lot? Some Empirical Evidence." In P.A. David and M.W. Reder, eds., Nations and Households in Economic Growth. (New York: Academic Press) 89-125.

Easterlin, R. A. (1995) "Will Raising the Incomes of All Increase the Happiness of All?" Journal of Economic Behaviour and Organization 27(1): 35-48.

Frey, Bruno S. and Alois Stutzer (2000) "Happiness, Economy and Institutions." Economic Journal 110(466): 918-38.

Frey, Bruno S. and Alois Stutzer (2002) Happiness and Economics. (Princeton: Princeton University Press)

Gravelle, H.(1998) "How Much of the Relation Between Population Mortality and Unequal Distribution of Income Is a Statistical Artefact?" British Medical Journal 316(7128): $382-5$. 
Grjebine, André (2000) “Tolérance zéro sur les routes.” Le Monde, May 26, page 19.

Helliwell, John F. (1996a) "Economic Growth and Social Capital in Asia." NBER Working Paper No. 5470 (Cambridge: National Bureau of Economic Research).

Helliwell, John F. (1996b) "Do Borders Matter For Social Capital? Economic Growth and Civic Culture in U.S. States and Canadian Provinces." NBER Working Paper No. 5863 (Cambridge: National Bureau of Economic Research).

Helliwell, John F. (1998) How Much Do National Borders Matter? (Washington DC: Brookings Institution Press).

Helliwell, John F. (2000) Globalization: Myths, Facts and Consequences. (Toronto: C.D. Howe Institute) (Benefactors Lecture 2000, available at www.CDHowe.org ).

Helliwell, John F. (2001a) "Social Capital, the Economy and Well-Being." In Keith Banting, Andrew Sharpe and France St-Hilaire, eds., The Review of Economic Performance and Social Progress (Montreal and Ottawa: Institute for Research on Public Policy and Centre for the Study of Living Standards).

Helliwell, John F. (2001b) The Contribution of Human and Social Capital to Sustained Economic Growth and Well-Being Editor and contributor. (Ottawa: HDRC, )(Proceedings of an OECD/HRDC conference, Quebec, March 19-21, 2000).

Inglehart, Ronald (1996) "The Diminishing Utility of Economic Growth: From Maximizing Security Toward Maximizing Subjective Well-Being." Critical Review 10(4): 509-31.

Inglehart, Ronald, et al (2000) World Values Surveys and European Values Surveys, 19811984, 1990-1993, and 1995-1997 (Computer File) ICPSR Version. (Ann Arbor, Michigan: Inter-university Consortium for Political and Social Research).

Iyengar S.S. and M.R. Lepper (1999) "Rethinking the Value of Choice: A Cultural Perspective on Intrinsic Motivation.” Journal of Personality and Social Psychology 76: 349-66. (Selecting from among fewer options increases satisfaction with the choices made)

Kasser, T. and R.M. Ryan (1993) "The Dark Side of the American Dream: Correlates of Financial Success as a Central Life Aspiration." Journal of Personality and Social Psychology 65: 410-22.

Kasser, T. and R.M. Ryan (1996) "Further Examining the American Dream: Differential Correlates of Intrinsic and Extrinsic Goals." Personality and Social Psychology Bulletin 22: 280-7. 
Kaufmann, Daniel, Aart Kraay and Pablo Zoido-Lobatoni (1999a) "Aggregating Governance Indicators.” World Bank Policy Research Department Working Paper 2195.

Kaufmann, Daniel, Aart Kraay and Pablo Zoido-Lobatoni (1999b) “Governance Matters.” World Bank Policy Research Department Working Paper 2195.

Kawachi, Ichiro, Bruce P. Kennedy, Kimberly Lochner, and Deborah Prothrow-Stith (1997) "Social Capital, Income Inequality, and Mortality." American Journal of Public Health 87(9) 1491-9.

Keller, Wolfgang (2000) "Geographic Localization of International Technology Diffusion." NBER Working Paper 7509. (Cambridge: National Bureau of Economic Research).

Knack, Stephen (2001) "Trust, Associational Life and Economic Performance.” In John F. Helliwell ed. The Contribution of Human and Social Capital to Sustained Economic Growth and Well-Being (Ottawa: HDRC, )(Proceedings of an OECD/HRDC conference, Quebec, March 19-21, 2000).

Knack, Stephen, and Philip Keefer (1997) "Does Social Capital have an Economic Payoff? A Country Investigation.” Quarterly Journal of Economics 112(4): 1251-88.

Lykken, D., and A. Tellegen (1996) "Happiness is a Stochastic Phenomenon." Psychological Science 7: 186-9.

Marer, Paul, and Salvatore Zecchini, eds. (1991) The Transition to a Market Economy: Volume 1- The Broad Issues. (Paris: OCED).

Mauro, Paulo (1995) “Corruption and Growth.” Quarterly Journal of Economics 110(3): 681712.

McCallum, John (1995) "National Borders Matter: Canada-U.S. Regional Trade Patterns." American Economic Review 85: (June): 615-23.

Michalos, Alex C., Bruno D. Zumbo and Anita Hubley (2000) "Health and the Quality of Life." Social Indicators Research 51: 245-86.

Moulton, Brent R. (1990) "An Illustration of a Pitfall in Estimating the Effects of Aggregate Variables on Micro Units.” Review of Economics and Statistics 72(2): 334-38.

Myers, David G. (2000) “The Funds, Friends and Faith of Happy People.” American Psychologist 55(1): 56-67.

Myers, David G. and Ed Diener (1995) "Who is Happy?" Psychological Science 6(1): 10-19 
Offer, Avner (2000) "Economic Welfare Measurements and Human Well-Being." University of Oxford Discussion Papers in Economic and Social History, Number 34 (March).

Okun, M.A. and L.K. George (1984) "Physician and Self-ratings of Health, Neuroticism and Subjective Well-Being Among Men and Women." Personality and Individual Differences 5: 533-40.

Olson, Mancur (1982) The Rise and Decline of Nations: Economic Growth, Stagflation and Social Rigidities (New Haven: Yale University Press).

Osberg, Lars G., and Andrew Sharpe (2001) "Comparisons of Trends in GDP and Economic Well-Being” In John F. Helliwell ed. The Contribution of Human and Social Capital to Sustained Economic Growth and Well-Being (Ottawa: HDRC, )(Proceedings of an OECD/HRDC conference, Quebec, March 19-21, 2000).

Oswald, A. J. (1997) “Happiness and Economic Performance” Economic Journal 107(445): 1815-31.

Organization for Economic Cooperation and Development (2001) The Well-Being of Nations: The Importance of Human and Social Capital (Paris: OECD)

Persson, Torsten, and Guido Tabellini (1994) “Is Inequality Harmful for Growth?” American Economic Review 84(3): 600-21.

Putnam, Robert D. (1995) "Tuning In, Tuning Out: The Strange Disappearance of Social Capital in America." PS: Political Science and Politics 28 (December): 664-83.

Putnam, Robert D. (2000) Bowling Alone: The Collapse and Revival of American Community. (New York: Simon \& Schuster).

Putnam, Robert D. (2001) "Social Capital: Measurement and Consequences." In John F. Helliwell ed. The Contribution of Human and Social Capital to Sustained Economic Growth and Well-Being (Ottawa: HDRC, )(Proceedings of an OECD/HRDC conference, Quebec, March 19-21, 2000).

Raiser, Martin (1997) "Informal Institutions, Social Capital and Economic Transition: Reflections on a Neglected Dimension." Working Paper 25 (London: European Bank for Reconstruction and Development).

Rose, Richard (2000) "How Much Does Social Capital Add to Individual Health?: A Survey Study of Russians." Social Science and Medicine. 
Schier, M.F. et al (1989) "Dispositional Optimism and Recovery From Coronary Artery Bypass Surgery: The Beneficial Effects on Physical and Psychological Well-Being." Journal of Personality and Social Psychology 57: 1024-40.

Smith, S. and P. Razzell (1975) The Pools Winners. (London: Caliban Books).

Tellegen, A., D.T. Lykken, T.J. Bouchard, K.J. Wilcox, N.L. Segal and S. Rich (1988) "Personality Similarity in Twins Reared Apart and Separately." Journal of Personality and Social Psychology 54: 1031-39.

Temple, J. (2001) "Growth Effects of Education and Social Capital in the OECD Countries." In John F. Helliwell ed. The Contribution of Human and Social Capital to Sustained Economic Growth and Well-Being (Ottawa: HDRC, )(Proceedings of an OECD/HRDC conference, Quebec, March 19-21, 2000).

Wilkinson, R.G. (1992) "Income Distribution and Life Expectancy" British Medical Journal 304(6820): 165-8.

Wilson, W. (1967) “Correlates of Avowed Happiness.” Psychological Bulletin 67: 294-306.

Wolfe, Barbara, and Robert Haveman (2001) "Accounting for the Social and Non-Market Effects of Education" In John F. Helliwell ed. The Contribution of Human and Social Capital to Sustained Economic Growth and Well-Being (Ottawa: HDRC, )(Proceedings of an OECD/HRDC conference, Quebec, March 19-21, 2000).

Wolfson, M., G. Kaplan, J. Lynch, N. Ross, and E. Backlund (1999) "The Relationship Between Inequality and Mortality is not a Statistical Artefact- An Empirical Demonstration." British Medical Journal 319: 953-7.

Woolcock, Michael (2001) "The Place of Social Capital in Understanding Social and Economic Outcomes." In John F. Helliwell ed. The Contribution of Human and Social Capital to Sustained Economic Growth and Well-Being (Ottawa: HDRC, )(Proceedings of an OECD/HRDC conference, Quebec, March 19-21, 2000).

Zak, and P. Knack (1998) "Trust and Growth.” IRIS Working Paper 219. (College Park: University of Maryland) 


\section{Table 1: Data Summary}

\begin{tabular}{|c|c|c|c|c|}
\hline & Min & Max & Mean & Std. Deviation \\
\hline life satisfaction & 1 & 10 & 6.79 & 2.37 \\
\hline state of health & 1 & 5 & 2.28 & 0.95 \\
\hline UNEMP & 0 & 1 & 0.0541 & 0.2263 \\
\hline MARRIED & 0 & 1 & 0.6217 & 0.485 \\
\hline ASMARR & 0 & 1 & 0.05059 & 0.2192 \\
\hline DIVORCED & 0 & 1 & 0.03876 & 0.193 \\
\hline SEPAR & 0 & 1 & 0.0168 & 0.1285 \\
\hline WIDOWED & 0 & 1 & 0.0641 & 0.2449 \\
\hline ED1619 & 0 & 1 & 0.3605 & 0.4802 \\
\hline ED2022 & 0 & 1 & 0.2654 & 0.4415 \\
\hline ED2329 & 0 & 1 & 0.06024 & 0.2379 \\
\hline AGE2534 & 0 & 1 & 0.2337 & 0.4232 \\
\hline AGE3544 & 0 & 1 & 0.2128 & 0.4093 \\
\hline AGE4554 & 0 & 1 & 0.1512 & 0.3582 \\
\hline AGE5564 & 0 & 1 & 0.1258 & 0.3316 \\
\hline AGE65UP & 0 & 1 & 0.1098 & 0.3127 \\
\hline CHURCH & 0 & 1 & 0.2221 & 0.4156 \\
\hline GOD & 0 & 1 & 0.3294 & 0.47 \\
\hline MEM12 & 0 & 8 & 0.1451 & 0.4964 \\
\hline MEM3 & 0 & 8 & 0.1988 & 0.6717 \\
\hline NOCHEAT & 0 & 1 & 0.546 & 0.4979 \\
\hline TRUST & 0 & 1 & 0.3444 & 0.4752 \\
\hline INCREL & 0.1 & 1 & 0.5001 & 0.2522 \\
\hline INCRELSQ & 0.01 & 1 & 0.3137 & 0.2756 \\
\hline LINCNAT & -3.34 & 0.0 & -1.1563 & 0.8849 \\
\hline INCNATSQ & 0 & 1.0 & 0.3137 & 0.2756 \\
\hline TRUSTNAT & 0.05 & 0.71 & 0.3443 & 0.1415 \\
\hline GOVTOT & -1 & 1.72 & 0.6483 & 0.7671 \\
\hline NOCHEATN & 0.05 & 0.81 & 0.5356 & 0.1612 \\
\hline CHURCHN & 0 & 0.9 & 0.243 & 0.2214 \\
\hline MEMN12 & 0 & 0.81 & 0.1596 & 0.1627 \\
\hline MEMN3 & 0 & 1.60 & 0.2030 & 0.3726 \\
\hline WAVE2 & 0 & 1 & 0.4721 & 0.4992 \\
\hline WAVE3 & 0 & 1 & 0.3561 & 0.4789 \\
\hline FSU & 0 & 1 & 0.1672 & 0.3732 \\
\hline EASTEUR & 0 & 1 & 0.09512 & 0.2934 \\
\hline LATAM & 0 & 1 & 0.1137 & 0.3174 \\
\hline ASIA & 0 & 1 & 0.1011 & 0.3014 \\
\hline OTHDEV & 0 & 1 & 0.07061 & 0.2562 \\
\hline SCAN & 0 & 1 & 0.09774 & 0.297 \\
\hline
\end{tabular}

Number of observations: 87806 
Equation 1: Well-Being Explained by Individual Variables

\begin{tabular}{lllll} 
& \multicolumn{2}{l}{ Coefficients } & $\mathrm{t}$ & Sig. \\
& $\mathrm{B}$ & \multicolumn{2}{l}{ Std. Error } & \\
(Constant) & 7.384 & 0.045 & 163.523 & 0 \\
state of health & -0.615 & 0.008 & -74.601 & 0 \\
UNEMP & -0.609 & 0.031 & -19.497 & 0 \\
MARRIED & 0.418 & 0.022 & 18.962 & 0 \\
ASMARR & 0.25 & 0.036 & 7.048 & 0 \\
DIVORCED & -0.0269 & 0.041 & -0.657 & 0.511 \\
SEPAR & -0.317 & 0.057 & -5.56 & 0 \\
WIDOWED & 0.00405 & 0.037 & 0.109 & 0.913 \\
ED1619 & -0.0480 & 0.018 & -2.66 & 0.008 \\
ED2022 & -0.0602 & 0.02 & -2.961 & 0.003 \\
ED2329 & 0.06219 & 0.033 & 1.858 & 0.063 \\
AGE2534 & -0.178 & 0.025 & -7.244 & 0 \\
AGE3544 & -0.332 & 0.027 & -12.296 & 0 \\
AGE4554 & -0.305 & 0.029 & -10.415 & 0 \\
AGE5564 & -0.0780 & 0.031 & -2.521 & 0.012 \\
AGE65UP & 0.237 & 0.034 & 7.018 & 0 \\
CHURCH & 0.104 & 0.019 & 5.544 & 0 \\
GOD & 0.34 & 0.018 & 19.283 & 0 \\
MEM12 & 0.05226 & 0.014 & 3.606 & 0 \\
MEM3 & 0.128 & 0.012 & 10.988 & 0 \\
NOCHEAT & 0.255 & 0.014 & 17.638 & 0 \\
TRUST & 0.257 & 0.015 & 16.859 & 0 \\
INCREL & 1.889 & 0.119 & 15.809 & 0 \\
INCRELSQ & -0.89 & 0.108 & -8.262 & 0 \\
WAVE2 & 0.261 & 0.022 & 12.07 & 0 \\
WAVE3 & -0.158 & 0.026 & -6.179 & 0 \\
FSU & -1.649 & 0.025 & -66.293 & 0 \\
EASTEUR & -0.748 & 0.027 & -27.709 & 0 \\
LATAM & -0.0015 & 0.027 & -0.056 & 0.955 \\
ASIA & -0.346 & 0.027 & -13.058 & 0 \\
OTHDEV & -0.741 & 0.031 & -23.539 & 0 \\
SCAN & 0.528 & 0.026 & 20.13 & 0 \\
& & & &
\end{tabular}

Model Summary

R Sq Adj R Square Std. Error of the Estimate $\begin{array}{lll}0.255 & 0.255 & 2.05\end{array}$

Dependent variable: Life satisfaction, on a scale of 1 to 10 . 
Equation 2: Well-Being Explained by Individual and Societal Variables

\begin{tabular}{lllll} 
& \multicolumn{2}{l}{ Coefficients } & $\mathrm{t}$ & $\mathrm{S}$ Sig. \\
& $\mathrm{B}$ & \multicolumn{2}{l}{ Std. Error } & \\
(Constant) & 6.965 & 0.077 & 90.10 & 0 \\
state of health & -0.608 & 0.008 & -73.92 & 0 \\
UNEMP & -0.587 & 0.031 & -18.84 & 0 \\
MARRIED & 0.429 & 0.022 & 19.56 & 0 \\
ASMARR & 0.238 & 0.035 & 6.71 & 0 \\
DIVORCED & -0.049 & 0.041 & -1.23 & 0.229 \\
SEPAR & -0.355 & 0.057 & -6.26 & 0 \\
WIDOWED & 0.013 & 0.037 & 0.15 & 0.714 \\
ED1619 & -0.691 & 0.018 & -3.74 & 0 \\
ED2022 & -0.660 & 0.021 & -3.20 & 0.001 \\
ED2329 & 0.0967 & 0.034 & 2.87 & 0.004 \\
AGE2534 & -0.193 & 0.024 & -7.88 & 0 \\
AGE3544 & -0.350 & 0.027 & -13.03 & 0 \\
AGE4554 & -0.333 & 0.029 & -11.44 & 0 \\
AGE5564 & -0.0993 & 0.031 & -3.22 & 0.001 \\
AGE65UP & 0.192 & 0.034 & 5.57 & 0 \\
CHURCH & 0.144 & 0.02 & 7.37 & 0 \\
GOD & 0.373 & 0.018 & 20.95 & 0 \\
MEM12 & 0.0330 & 0.015 & 2.29 & 0.026 \\
MEM3 & 0.0636 & 0.012 & 5.15 & 0 \\
NOCHEAT & 0.225 & 0.015 & 15.49 & 0 \\
TRUST & 0.240 & 0.015 & 15.87 & 0 \\
INCREL & 1.903 & 0.12 & 15.87 & 0 \\
INCRELSQ & -0.955 & 0.108 & -8.82 & 0 \\
LINCNAT & 0.265 & 0.025 & 15.87 & 0 \\
INCNATSQ & -0.773 & 0.090 & -8.54 & 0 \\
TRUSTNAT & 0.319 & 0.112 & 2.84 & 0.005 \\
GOVTOT & 0.317 & 0.026 & 12.03 & 0 \\
NOCHEATN & 0.263 & 0.061 & 4.29 & 0 \\
CHURCHN & 0.161 & 0.054 & 3.01 & 0.003 \\
MEMN12 & 0.578 & 0.076 & 7.57 & 0 \\
MEMN3 & 0.576 & 0.038 & 14.98 & 0 \\
EDATTNAT & 0.0051 & 0.007 & 0.71 & 0.474 \\
WAVE2 & 0.215 & 0.025 & 8.73 & 0 \\
WAVE3 & -0.280 & 0.040 & -7.08 & 0 \\
FSU & -0.815 & 0.058 & -13.98 & 0 \\
EASTEUR & -0.465 & 0.045 & -10.44 & 0 \\
LATAM & 0.322 & 0.041 & 7.92 & 0 \\
ASIA & -0.054 & 0.045 & 1.21 & 0.226 \\
OTHDEV & -0.124 & 0.052 & -2.39 & 0 \\
SCAN & 0.445 & 0.040 & 11.10 & 0
\end{tabular}

Model Summary

R Sq Adj R Square Std. Error of the Estimate $\begin{array}{lll}0.263 & 0.263 & 2.04\end{array}$

Dependent variable: Life satisfaction, on a scale of 1 to 10 . 
Equation 3: Individual and National Effects of Education on Well-Being Coefficients $t \quad$ Sig.

\begin{tabular}{lllll} 
& B & \multicolumn{3}{l}{ Std. Error } \\
(Constant) & 6.51 & 0.044 & 146.635 & 0 \\
ED1619 & 0.119 & 0.019 & 6.403 & 0 \\
ED2022 & 0.242 & 0.02 & 11.951 & 0 \\
ED2329 & 0.425 & 0.034 & 12.335 & 0 \\
EDATTNAT & 0.06778 & 0.004 & 16.57 & 0 \\
WAVE2 & 0.202 & 0.022 & 8.959 & 0 \\
WAVE3 & -0.163 & 0.026 & -6.402 & 0 \\
FSU & -2.389 & 0.024 & -98.745 & 0 \\
EASTEUR & -1.154 & 0.028 & -41.216 & 0 \\
LATAM & 0.117 & 0.032 & 3.702 & 0 \\
ASIA & -0.275 & 0.031 & -8.946 & 0 \\
OTHDEV & -0.319 & 0.04 & -7.975 & 0 \\
SCAN & 0.592 & 0.027 & 22.027 & 0
\end{tabular}

Model Summary

$\begin{array}{lll}\text { R Sq } & \text { Adj R Square } & \text { Std. Error of the Estimate } \\ 0.161 & 0.161 & 2.17\end{array}$

Dependent variable: Life satisfaction, on a scale of 1 to 10 . 
Equation 4: Effects of Education Including All Individual Variables

$$
\begin{array}{lrr}
\text { Coefficients } & \text { t } & \text { Sig. } \\
\text { B } & \text { Std. Error }
\end{array}
$$

$\begin{array}{lllll}\text { (Constant) } & 6.981 & .058 & 119.509 & .000 \\ \text { state of health } & -.612 & .008 & -74.205 & .000 \\ \text { UNEMP } & -.606 & .031 & -19.417 & .000 \\ \text { MARRIED } & .415 & .022 & 18.864 & .000 \\ \text { ASMARR } & .234 & .036 & 6.576 & .000 \\ \text { DIVORCED } & -.0518 & .041 & -1.262 & .207 \\ \text { SEPAR } & -.333 & .057 & -5.848 & .000 \\ \text { WIDOWED } & -.00342 & .037 & -.092 & .927 \\ \text { ED1619 } & -.0881 & .018 & -4.790 & .000 \\ \text { ED2022 } & -.0903 & .021 & -4.400 & .000 \\ \text { ED2329 } & .0517 & .033 & 1.545 & .122 \\ \text { AGE2534 } & -.186 & .025 & -7.568 & .000 \\ \text { AGE3544 } & -.343 & .027 & -12.727 & .000 \\ \text { AGE4554 } & -.321 & .029 & -10.974 & .000 \\ \text { AGE5564 } & -.101 & .031 & -3.259 & .001 \\ \text { AGE65UP } & .197 & .034 & 5.801 & .000 \\ \text { CHURCH } & .130 & .019 & 6.877 & .000 \\ \text { GOD } & .339 & .018 & 19.223 & .000 \\ \text { MEM12 } & .0481 & .014 & 3.321 & .001 \\ \text { MEM3 } & .123 & .012 & 10.545 & .000 \\ \text { NOCHEAT } & .251 & .014 & 17.359 & .000 \\ \text { TRUST } & .247 & .015 & 16.205 & .000 \\ \text { INCREL } & 1.967 & .120 & 16.449 & .000 \\ \text { INCRELSQ } & -.998 & .108 & -9.237 & .000 \\ \text { EDATTNAT } & .0434 & .004 & 10.866 & .000 \\ \text { WAVE2 } & .263 & .022 & 12.149 & .000 \\ \text { WAVE3 } & -.182 & .026 & -7.116 & .000 \\ \text { FSU } & -1.634 & .025 & -65.596 & .000 \\ \text { EASTEUR } & -.723 & .027 & -26.682 & .000 \\ \text { LATAM } & .170 & .031 & 5.503 & .000 \\ \text { ASIA } & -.198 & .030 & -6.656 & .000 \\ \text { OTHDEV } & -.496 & .039 & -12.840 & .000 \\ \text { SCAN } & .551 & .026 & 20.956 & .000\end{array}$

Model Summary

$$
\begin{array}{lll}
\text { R Sq } & \text { Adj R Square } & \text { Std. Error of the Estimate } \\
0.256 & 0.256 & 2.04
\end{array}
$$

Dependent variable: Life satisfaction, on a scale of 1 to 10 . 
Equation 5: Estimated by survey ordered probit with robust standard errors

\begin{tabular}{|c|c|c|c|c|c|c|}
\hline Well-being & Coef. & Std. Err. & t & $\mathrm{P}>|\mathrm{t}|$ & [95\% Conf. & Interval] \\
\hline ill-health & -.3098529 & .011971 & -25.88 & 0.000 & -.3339221 & -.2857836 \\
\hline unemoecd & -.3264395 & .0357645 & -9.13 & 0.000 & -.3983488 & -.2545302 \\
\hline unemrest & -.255049 & .0630927 & -4.04 & 0.000 & -.3819054 & -.1281927 \\
\hline married & .2193904 & .017063 & 12.86 & 0.000 & .1850829 & .253698 \\
\hline asmarr & .1500514 & .0316425 & 4.74 & 0.000 & .0864299 & .2136728 \\
\hline divorced & -.0280857 & .0227729 & -1.23 & 0.223 & -.0738737 & .0177023 \\
\hline separ & -.1313658 & .0418161 & -3.14 & 0.003 & -.2154426 & -.047289 \\
\hline age 2534 & -.0878339 & .013226 & -6.64 & 0.000 & -.1144266 & -.0612412 \\
\hline age 3544 & -.160897 & .0152974 & $-10 \cdot 52$ & 0.000 & -.1916544 & -.1301396 \\
\hline age 4554 & -.1365462 & .014558 & -9.38 & 0.000 & -.1658171 & -.1072754 \\
\hline age65up & .1437093 & .0265991 & 5.40 & 0.000 & .0902282 & .1971905 \\
\hline church & .0633395 & .022735 & 2.79 & 0.008 & .0176278 & .1090512 \\
\hline god & .2448375 & .0260924 & 9.38 & 0.000 & .1923753 & .2972998 \\
\hline memtot & .0320677 & .0097842 & 3.28 & 0.002 & .0123954 & .0517401 \\
\hline nocheat & .1345062 & .0180847 & 7.44 & 0.000 & .0981445 & .1708679 \\
\hline trust & .1206647 & .0128723 & 9.37 & 0.000 & .0947832 & .1465463 \\
\hline dec 4 oecd & .0752419 & .0282683 & 2.66 & 0.011 & .0184046 & .1320792 \\
\hline dec5oecd & .1134835 & .0248328 & 4.57 & 0.000 & .0635537 & .1634132 \\
\hline dec6oecd & .1197484 & .035544 & 3.37 & 0.001 & .0482823 & .1912144 \\
\hline dec7oecd & .1098875 & .031298 & 3.51 & 0.001 & .0469586 & .1728165 \\
\hline dec8oecd & .1143382 & .0334174 & 3.42 & 0.001 & .0471481 & .1815283 \\
\hline dec9oecd & .0995473 & .036428 & 2.73 & 0.009 & .0263039 & .1727907 \\
\hline d10oecd & .1727459 & .0692726 & 2.49 & 0.016 & .033464 & .3120278 \\
\hline dec3rest & .1474467 & .03297 & 4.47 & 0.000 & .0811561 & .2137374 \\
\hline dec 4 rest & .210999 & .0405087 & 5.21 & 0.000 & .1295509 & .2924471 \\
\hline dec5rest & .2757988 & .0472885 & 5.83 & 0.000 & .1807189 & .3708787 \\
\hline dec6rest & .2956818 & .0509826 & 5.80 & 0.000 & .1931745 & .3981891 \\
\hline dec7rest & .403393 & .056085 & 7.19 & 0.000 & .2906266 & .5161595 \\
\hline dec8rest & .4346364 & .0600677 & 7.24 & 0.000 & .3138623 & .5554105 \\
\hline dec9rest & .4726356 & .0578563 & 8.17 & 0.000 & .3563077 & .5889635 \\
\hline d10rest & .573604 & .0730342 & 7.85 & 0.000 & .426759 & .720449 \\
\hline y2050 & .0911829 & .0832137 & 1.10 & 0.279 & -.0761295 & .2584953 \\
\hline y5075 & .0480333 & .1065739 & 0.45 & 0.654 & -.1662478 & .2623144 \\
\hline yover 75 & .0105645 & .1051811 & 0.10 & 0.920 & -.2009163 & .2220453 \\
\hline govtot & .2350489 & .0575888 & 4.08 & 0.000 & .1192589 & .3508388 \\
\hline memntot & .232473 & .0952784 & 2.44 & 0.018 & .0409029 & .424043 \\
\hline wave 3 & -.2074443 & .0539673 & -3.84 & 0.000 & -.3159529 & -.0989358 \\
\hline fsu2 & -.3307758 & .0714761 & -4.63 & 0.000 & -.4744882 & -.1870634 \\
\hline fsu 3 & -.5388172 & .0805434 & -6.69 & 0.000 & -.7007606 & -.3768737 \\
\hline easteur2 & -.4238132 & .0783556 & -5.41 & 0.000 & -.5813577 & -.2662686 \\
\hline scan & .2144182 & .0554557 & 3.87 & 0.000 & .1029169 & .3259194 \\
\hline / cut 1 & -2.258001 & .1180448 & -19.13 & 0.000 & -2.495346 & -2.020656 \\
\hline / cut 2 & -2.005684 & .1087071 & -18.45 & 0.000 & -2.224254 & -1.787114 \\
\hline / cut 3 & -1.619015 & .0969314 & -16.70 & 0.000 & -1.813909 & -1.424121 \\
\hline / cut 4 & -1.31311 & .0918048 & $-14 \cdot 30$ & 0.000 & -1.497696 & -1.128524 \\
\hline / cut 5 & -.779954 & .0870779 & -8.96 & 0.000 & -.9550359 & -.6048721 \\
\hline$/ \operatorname{cut} 6$ & -.4315701 & .0882769 & -4.89 & 0.000 & -.6090627 & -.2540774 \\
\hline / cut 7 & .0083922 & .0883394 & 0.09 & 0.925 & -.169226 & .1860105 \\
\hline / cut 8 & .6670761 & .0864617 & 7.72 & 0.000 & .4932332 & .840919 \\
\hline / cut 9 & 1.159699 & .0917754 & 12.64 & 0.000 & .9751721 & 1.344226 \\
\hline
\end{tabular}

